prime objective, but in our view the time for reducing the duration of the curriculum up to full registration does not appear to have come." In my own university, despite the unusual distinction of its teachers, progressive assessment of students has not yet been accepted as either possible or desirable. The risk that the Council foresees is displayed as eloquently as it could be " that in these matters of assessing and testing students a teacher will see and approve the better, but follow the worse course." The time exacted from the student in written examination time in anatomy, physiology, and biochemistry in the reformed medical course is to rise from six to eleven hours. Despite the best intentions change is not always synonymous with improvement.

Much also remains for the universities to do in supervising pre-registration appointments, and particularly in providing an advisory service in postgraduate appointments to its own graduates; and we have seen neither teaching nor examination practices match the changes in ideas that have occurred in educational leadership. "New wine" poured into "old bottles" is not a remedy for instant success. Nevertheless the attitude of mind has changed, and in circles which are less conservative than universities that change of attitude has found practical expression, as in this institute whose opening we celebrate today.

\section{Lesson from Medicine}

May I return to my original theme? As we have seen, the key to the liberation of medicine was the recognition that educa- tion does not, and should not, and indeed cannot, end with university degree. That degree should not be the end, it should merely be the end of the beginning. This is not a new idea. Winston Churchill remarked to the undergraduates at Bristol University in 1929: "The most important thing about education is appetite. Education does not begin with the university and it certainly ought not to end there." Education in Britain can be shaped to help our young to lead enjoyable, satisfying, and useful lives, but it will be so shaped only when this elementary truth has sunk into our masters and the British public. If we established graduate schools for the advanced study of the arts and the sciences, and if we established graduate schools to train technocrats and all the managerial classes, through business managers, insurance agents, to local government officials, then it would bc possible to liberate the undergraduate curriculum and to stop once and for all that hideous Solomon's choice that we exact from our young. They will no longer be asked to abandon the arts or the sciences on the brink of puberty and thus deny themselves for the rest of their lives participation in half of the intellectual ventures in mankind.

If we furnish the stimulus, the opportunity, and the facilities for self-education throughout life, schoolmaster, business man, engineer, and those who conduct our public affairs can remain au courant with changing knowledge, thought, and practice. The leisured can use their leisure with profit and enjoyment. But none of those things will come without a changed attitude - a realization that school and university are merely phases in a life-long process of self-education. How long, O Lord, how long?

\title{
Analgesic Nephropathy. Clinical Course after Withdrawal of Phenacetin
}

\author{
DAVID BELL,* M.B., B.S., B.SC. ; DAVID N. S. KERR, † M.SC., F.R.C.P., F.R.C.P.ED. \\ JOHN SWINNEY, $\ddagger$ M.C., M.D., M.S., F.R.C.S. ; W. KEITH YEATES, $\ddagger$ M.D., M.S., F.R.C.S.
}

British Medical fournal, 1969, 3, 378-382

\begin{abstract}
Uummary : Of 14 patients with analgesic nephropathy 11 $\checkmark$ were followed up for 9 to 88 (mean 36) months after withdrawal of analgesics containing phenacetin. Ten of these 11 are still alive and have improving, static, or very slowly declining renal function. Analgesic withdrawal is therefore worth achieving even ic the presence of advanced renal failure. Careful prolonged follow-up is required to prevent or detect relapse and to deal with the complications of prolonged renal failure, particularly bone disease and acidosis.

Early diagnosis is life-saving in this condition. Attention is drawn to the diagnostic value of sterile pyuria, but the best screening test for the condition is careful interrogation of all patients with chronic renal disease of unknown aetiology; analgesic intake is rarely denied if asked for specifically.
\end{abstract}

\section{Introduction}

Prolonged high intake of analgesic mixtures containing phenacetin causes interstitial nephritis and papillary necrosis, resulting in tubular dysfunction, decrease in glomerular filtration rate, azotaemia, and death. The progressive events that follow experimental papillary ablation (Lucke et al., 1968) might lead one to expect an inexorable downhill course in this disease even if the nephrotoxin were withdrawn. Our experience suggests, on the contrary, that the disease can be arrested at a very late stage and emphasizes the importance of diagnosis even in the presence of apparently terminal renal failure.

Our total experience of analgesic nephropathy is presented in the accompanying Table; illustrative case histories are presented below and in Figs. 1-4.

\section{Case 1}

A 34-year-old woman was admitted to hospita! in January 1962 with a history of nocturia for several months, and malaise, vomiting, epistaxis, and acidotic breathing for two months. She had taken barbiturates in excess for two years, and we later obtained a history of excessive intake of compound codeine tablets for headaches over six years. She was oliguric and clinically azotaemic,

\footnotetext{
* Senior House Officer in Rheumatology, Royal Victoria Infirmary, Newcastle upon Tyne NE1 4LP.

+ Professor of Medicine, University of Newcastle upon Tyne NE1 4LP. ‡ Consultant Urological Surgeon, Newcastle General Hospital, Newcastle upon Tyne NE4 6BE.
} 
with a plasma urea of $470 \mathrm{mg} . / 100 \mathrm{ml}$. During emergency haemodialysis she developed a severe disequilibrium syndrome and had a memory gap of several days.

Her intake of analgesics stopped spontaneously during her hospital admission, and apart from a spell of three months in 1966 she has taken few analgesics since. On discharge from hospital in March 1962 her blood pressure (B.P.) was 180/105 and her plasma urea $240 \mathrm{mg} . / 100 \mathrm{ml}$. Proteinuria was slight and inconstant, but pyuria was persistent in spite of repeatedly sterile midstream urine cultures. Renal biopsy showed interstitial nephritis. She was assumed to have a poor prognosis.

Her plasma urea subsequently fell to about $100 \mathrm{mg} . / 100 \mathrm{ml}$. Her creatinine clearance between 1962 and 1969 varied between 6 and $11 \mathrm{ml} . / \mathrm{min}$., with a median of about $7 \mathrm{ml} . / \mathrm{min}$. (Fig. 1). She has been normotensive for much of this time, but peaks of hypertension up to $190 / 130$ have occurred, particularly during vitamin-D therapy and her relapse to analgesic intake. Her acidosis has always become severe (plasma bicarbonate $\left(\mathrm{HCO}_{3}\right) 4-7 \mathrm{mEq} / \mathrm{l}$.) when she has stopped taking sodium bicarbonate because of ankle oedema. For the past year both oedema and hypertension have been controlled by frusemide $40-80 \mathrm{mg}$./day. Polyuria and nocturia are her only urinary symptoms. Two urinary infections responded rapidly to antibacterial agents. Her anaemia has been partly ironresponsive and aggravated by episodes of melaena from a duodenal ulcer.

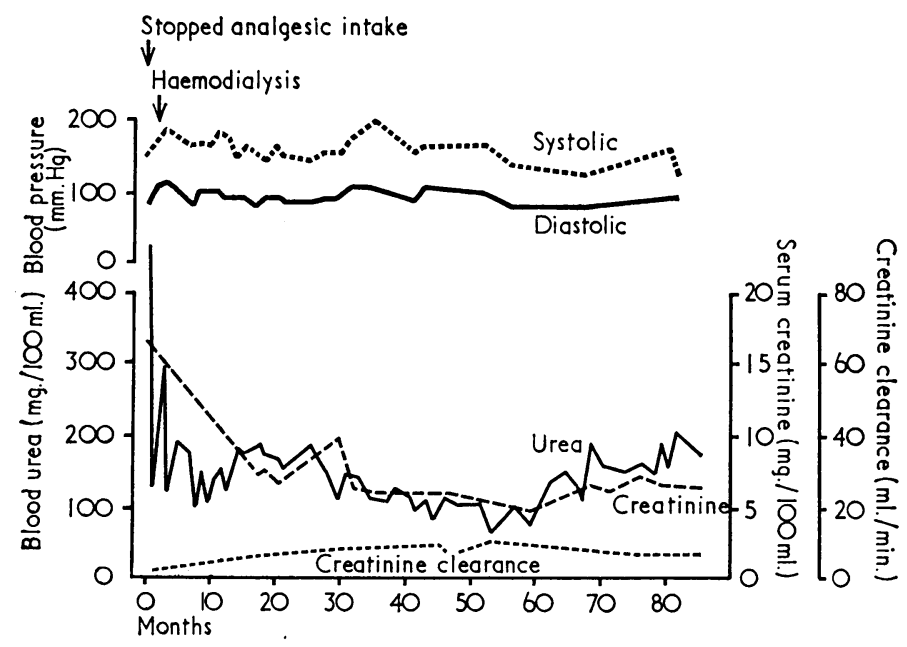

FIG. 1.-Case 1.

During 1966 her serum alkaline phosphatase rose steadily to 208 international units (i.u.), and a skeletal survey showed renal osteodystrophy. A six-month course of vitamin D 50,000 units daily restored bone radiographs and serum alkaline phosphatase to normal but produced conjunctivitis from calcium deposition. During 1966-9 she had attacks of pain in elbow, foot, and hand, suggestive of secondary gout and responding to indomethacin. Her serum uric acid varied between 7.2 and $12.7 \mathrm{mg} . / 100 \mathrm{ml}$. before the start of diuretic therapy, and subsequently rose to $15.4 \mathrm{mg} . / 100 \mathrm{ml}$. At the time of writing she was receiving allopurinol.

In spite of these vicissitudes she has remained in reasonable health for over seven years, bringing up her family single-handed, working part time, and doing voluntary work in hospital.

\section{Case 2}

A woman of 62 presented in August 1963 at Blackburn Royal Infirmary with cervical spondylosis. Her B.P. was 210/120, plasma urea $54 \mathrm{mg} . / 100 \mathrm{ml}$., haemoglobin $10.0 \mathrm{~g} . / 100 \mathrm{ml}$. In February 1964 she had haematuria and left loin pain; plasma urea was 62 mg./100 ml. (Fig. 2). Intravenous pyelography showed faint excretion in April but was normal in September. She had further attacks of loin pain in August and December. Retrograde pyelography in March 1965 showed contracted kidneys with normal collecting systems.

In December 1964 the compound codeine, Sonalgin, and Anadin she was taking for relief of neck pain were stopped, and she was tried on a variety of alternatives, including soluble aspirin, paracetamol, and Equagesic. So far as we can ascertain she took no phenacetin during the next six months, but her renal function continued to decline, her plasma urea reaching $276 \mathrm{mg} . / 100 \mathrm{ml}$. in June 1965, when she moved to Durham and came under our care. She was azotaemic (creatinine $9.8 \mathrm{mg} . / 100 \mathrm{ml}$.), acidotic $\left(\mathrm{HCO}_{3} 10 \mathrm{mEq} / \mathrm{l}\right.$.),

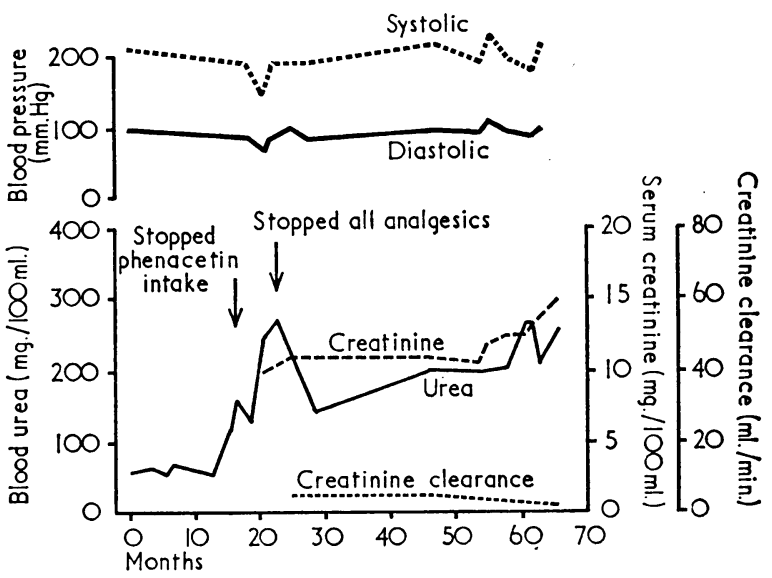

Fig. 2.-Case 2.

and anaemic ( $\mathrm{Hb} 4.4 \mathrm{~g} . / 100 \mathrm{ml}$.). Her creatinine clearance was $5 \mathrm{ml} . / \mathrm{min}$. Her life expectation was estimated in weeks rather than months.

Since June 1965 her analgesic therapy has been codeine phosphate, with short spells on indomethacin and mefenamic acid. Her renal function declined very slowly, the creatinine rising only from 9.8 to $12.8 \mathrm{mg} . / 100 \mathrm{ml}$. over three years. In July 1967 she was started on sodium bicarbonate for severe acidosis (plasma $\mathrm{HCO}_{3}$ $3 \mathrm{mEq} / \mathrm{l}$.) and on vitamin D 50,000 units daily for renal bone disease with widespread bone pain. In January 1969 her serum calcium rose to $12.7 \mathrm{mg} . / 100 \mathrm{ml}$. and she developed a severe urinary infection; her renal function fell rapidly (creatinine clearance from 3.5 down to $1.7 \mathrm{ml} . / \mathrm{min}$.) and has not returned to its previous level with treatment of the urinary infection and withdrawal of vitamin $D$.

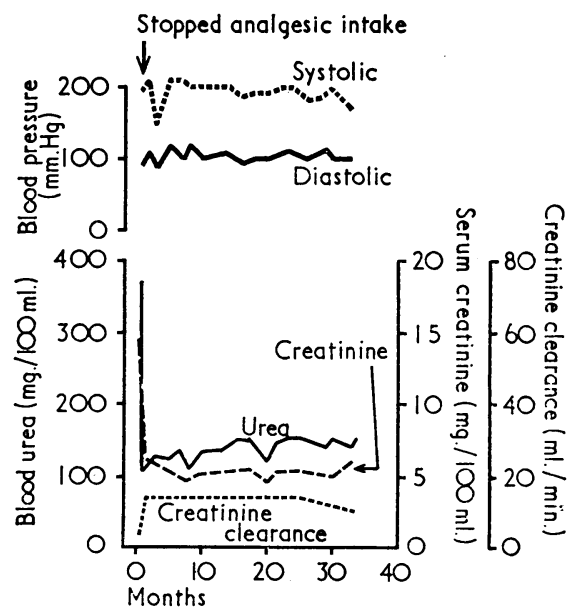

Fig. 3.-Case 3.

For three unexpected years she enjoyed reasonable health, though the substitute analgesics were much less effective in relieving her neck pain than the phenacetin-containing mixtures she had previously taken. At the time of writing she was in preterminal renal failure.

\section{Case 3}

A 52-year-old woman presented in May 1966 with tinnitus, pruritus, and vomiting. She had taken compound codeine tablets over many years for headaches. Like Case 1 she had noticed cyanosis of the lips when taking these tablets. Her B.P. was 195/ 
95, urinary specific gravity was fixed at $1,010, \mathrm{Hb} 8.9$ g./100 ml., plasma urea $370 \mathrm{mg} . / 100 \mathrm{ml}$., $\mathrm{HCO}_{3} 6 \mathrm{mEq} / \mathrm{l}$. (Fig. 3). With rehydration and low-protein diet she improved and her plasma urea became stabilized at about $120 \mathrm{mg} . / 100 \mathrm{ml}$; creatinine $5 \mathrm{mg} . / 100$ $\mathrm{ml}$; creatinine clearance $13 \mathrm{ml} . / \mathrm{min}$. She had three episodes of renal colic in 1966.

She stopped phenacetin-containing drugs in May 1966, but took paracetamol 2-4 g./day during 1966-8. She is now taking no analgesics and has remained well, apart from radiological and biochemical evidence of renal bone disease in 1968 ; blood pressure control was particularly difficult during the nine months of vitamin-D therapy. In February 1969 her plasma urea was $155 \mathrm{mg} . / 100 \mathrm{ml}$., creatinine $6.2 \mathrm{mg} . / 100 \mathrm{ml}$., creatinine clearance $10 \mathrm{ml} . / \mathrm{min}$., and B.P. was controlled with methyldopa and frusemide.

\section{Case 4}

A woman of 52 presented in February 1966 with a grand-mal seizure and gave a history of recent polydypsia, polyuria, vomiting, and loss of weight. For 12 years she had taken compound codeine tablets $2 /$ night for pain from varicose ulceration. Her B.P. was $140 / 90$, Hb 5.9 g./100 ml., plasma urea $195 \mathrm{mg} . / 100 \mathrm{ml}$., creatinine $7.4 \mathrm{mg} . / 100 \mathrm{ml}$., creatinine clearance $11 \mathrm{ml} . / \mathrm{min}$. (Fig. 4). An intravenous pyelogram showed bilateral clubbed calices. Analgesics were stopped and she was discharged on a $40-\mathrm{g}$. protein diet. For the next 28 months she did well with a stable plasma urea (around $120 \mathrm{mg} . / 100 \mathrm{ml}$.) and creatinine (around $6 \mathrm{mg} . /$ $100 \mathrm{ml}$.). In June 1968 she required peritoneal dialysis for fluid overload during a chest infection. In August she developed a urinary infection followed by pneumonia due to the same organism. She died in October 1968 ; the kidneys were shrunken, with necrotic papillae, and there were multiple lung abscesses.

\section{Diagnostic Criteria}

Analgesic nephropathy is generally thought to occur only in patients who have consumed several kilograms of phenacetin (in analgesic or sedative mixtures) over many years. All our patients met this criterion. Though paracetamol (Krikler, 1967) and aspirin (Prescott, 1969) have been blamed for isolated cases of papillary necrosis, these reports are rare; we have encountered no patient with other features of the disease who had not consumed phenacetin, and this was the only drug common to all our patients (see Table).
In this setting the diagnosis can be made with confidence if whole kidneys are available for pathological examination. Three of our patients came to necropsy and one had bilateral nephrectomy at the time of transplantation. All showed the typical findings of smooth renal outlines with shallow depres-

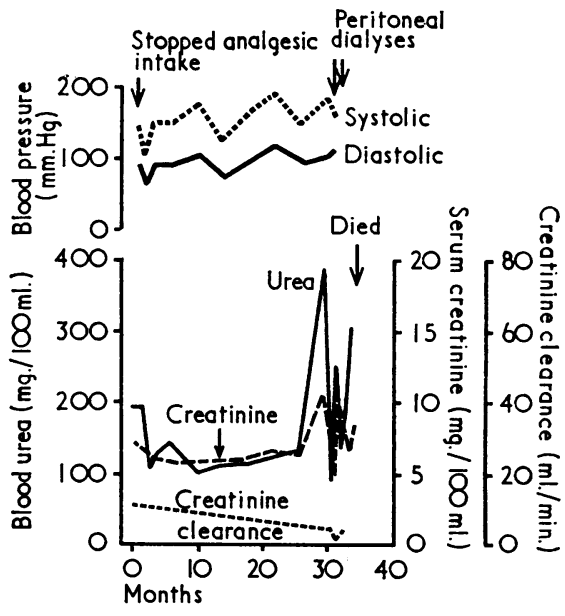

Fig. 4.-Case 4.

sions, necrotic papillae, severe diffuse tubular atrophy, interstitial fibrosis with round-cell infiltration, and mild glomerulosclerosis (Burry et al., 1966 ; Kincaid-Smith, 1967). Occasionally separated papillae can be shown pyelographically (Lindvall, 1960) or can be recovered from the urine and examined histologically; this was possible in only one of our patients.

In the remainder the presumptive diagnosis is based on a history of polyuria, polydipsia, and impaired concentrating power in the absence of any other chronic renal disease. No patient gave a history of glomerulonephritis, and proteinuria was absent or slight (below $3 \mathrm{~g} . / 24$ hours) in all. While pyelography helped to exclude obstruction and polycystic disease, it did not always differentiate between analgesic nephropathy and chronic pyelonephritis, which produce very similar pictures clinically, and on renal function tests (Bengtsson, 1967). None of our patients, however, gave a history of recurrent or chronic urinary infection.

W.C.E.T. = White cell excretion rate.

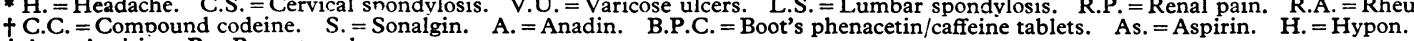
$\neq$ As. = Aspirin. P. = Paracetamol. f Patients usualiy quoted intake as a range-e.g., 8-12 tablets daily. Total intake was calculated from the lowest intake given.

Summary of Cases

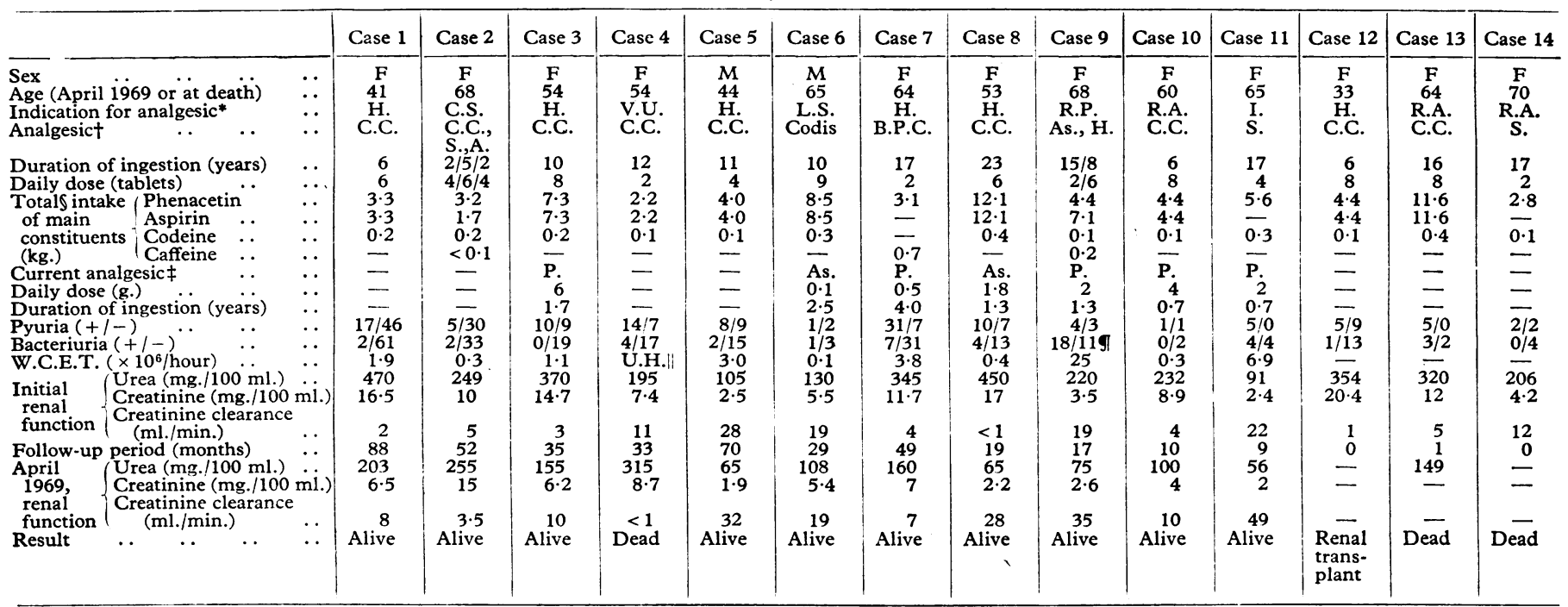




\section{Clinical Features}

Age at presentation ranged from 33 to 70 years. All but two were women; both men were medically qualified. Seven patients had attacks of renal colic. One (Case 9), who had undergone nephrectomy for pyonephrosis in 1944, developed acute renal failure from obstruction of her remaining ureter by a necrotic papilla. Four had peptic ulceration-a similar incidence to the $6 / 36$ recorded by Prescott (1966). Three of four patients had mild reticulocytoses during analgesic intake (Harvald, 1963) and two had gall stones (Maisel and Priest, 1964). Hypertension was not particularly troublesome (Larsen and Møller, 1959); two of our patients were normotensive throughout and only five required hypotensive therapy.

Pyuria was a common feature; if our experience is typical, analgesic nephropathy has overtaken renal tuberculosis as the commonest cause of sterile pyuria in the United Kingdom. "Significant pyuria" (10+ cells per high-power field) was present in 114 out of 243 examinations (47\%) in 13 patients. Only $30(14 \%)$ of these midstream urine samples yielded a growth of 100,000 or more bacteria per ml. Quantitative white cell counts (see Table I) ranged up to several million per ml., and Case 4 had uncountable white cells causing milky urine with negative cultures. Renal tuberculosis was excluded by urine culture or/and examination of whole kidneys.

\section{Renal Radiology}

Twelve patients had intravenous pyelography. Separated papillae were never found. In three patients the calices were clubbed, but papillary necrosis without separation was shown at necropsy. In eight cases the first diagnosis suggested by the radiologist was chronic pyelonephritis; seven had small kidneys, five had clubbed calices, and in three the outline was lobulated. In two of these the lobulation was described as " foetal." Four patients had a total of 10 normal intravenous pyelographic examinations (Fairley and Kincaid-Smith, 1968).

\section{Drug Intake History}

All of these patients were seen initially by one or more doctors (sometimes ourselves), who failed to elioit the history of analgesic intake. The difficulty of obtaining an accurate history has been noted by others (Maisel and Priest, 1964 ; Young et al., 1965) and attributed to concealment by the patient. None of our patients denied the analgesic intake on direct questioning, but several had omitted any reference to these drugs in a previous routine "drug history" because they regarded analgesics as harmless domestic remedies unworthy of special mention.

Clinical suspicion of analgesic nephropathy should be aroused by any of the following in a patient with renal disease: anaemia (particularly haemolytic) out of proportion to azotaemia, sterile pyuria, attacks of renal colic without stone, chronic headache or arthritis, multiple complaints in middleaged women. Diagnosis or suspicion of this condition at a very early stage, however, must depend on direct questioning of patients. The inclusion of an "analgesic history" in the routine questionary distributed to patients at our renal clinic led to the diagnosis in four of our patients.

\section{Withdrawal of Phenacetin}

Two patients presented with terminal pyelonephritis and septicaemia ; one of these has previously been reported (Walls et al., 1968). Another had such severe chronic renal failure that she was at once started on regular haemodialysis. The remaining 11 were weaned off analgesic mixtures containing phenacetin. Withdrawal was easier than we expected in view of the many reports from Scandinavia, Switzerland, and Australia that nephropathy is usually associated with habituation to the drugs. The cycle of "headache-analgesic-withdrawal headache-more analgesic" was broken for several of $\stackrel{\unrhd}{\varrho}$ our patients by critical azotaemia and hospital admission. $\subseteq$ Three patients who took pills for the warm glow they induced or other inadequate indications have proved more difficult, and one has since been addicted to dextromoramide. Some patients were reluctant to accept the role of analgesics in the genesis of their renal disease, and constant probing has been necessary at follow-up to detect relapse.

Our major problem has been the provision of a satisfactory alternative to phenacetin-containing mixtures for those $\overrightarrow{0}$ patients with chronic organic pain. Since neither aspirin nor paracetamol is free of all suspicion of nephrotoxicity (Gilman, $\vec{\omega}$ 1964 ; Bulger et al., 1968 ; Prescott, 1969) we have been reluctant to use them in adequate dosage in patients with established renal damage. Codeine and its analogues have proved $\dot{\omega}$ ineffective and other analgesics have their own hazards, which 0 are increased by the presence of renal failure.

\section{Clinical Course after Phenacetin Withdrawal}

All 11 patients who were followed after phenacetin with- $\vec{\sigma}$ drawal had an initial improvement in renal function which $\longrightarrow$ was no doubt due in part to correction of dehydration and infection. Thereafter seven have had a slow improvement in $\bar{\oplus}$ renal function, three remained stable (including Case 4 for the $\vec{\bullet}$ first 28 months), and one has had a very slow decline in renal function (Fig. 5).

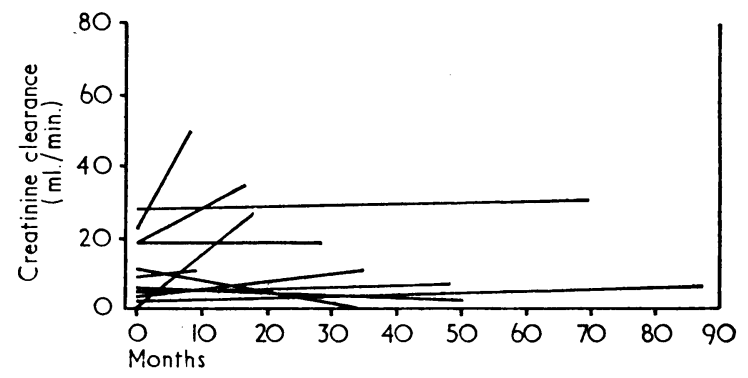

FIG. 5.-Creatinine clearance at beginning and end of followup in 11 patients.

Improvement following analgesic withdrawal at a stage when 윽 considerable renal function is preserved has been previously $N$ described (Gault et al., 1968) and is not surprising. What is $D$ more impressive is the relatively long survival of patients whose creatinine clearance, even after the initial improvement, was in the range $5-15 \mathrm{ml} . / \mathrm{min}$. Though individual patients with other chronic renal diseases have equally prolonged survival, these $\mathrm{C}$ patients as a group have long outlived any comparable group of patients (including those with polycystic kidneys) under our care.

Prolonged survival in chronic renal failure brings in its train several complications. Four of our patients have developed renal bone disease and one has secondary gout. Acidosis has been a constant feature, and its treatment has complicated the already precarious electrolyte homoeostasis. Three patients have required readmission for acute-on-chronic renal failure due to salt-and-water depletion, while others have required diuretics 8 for oedema and hypertension. Both potassium depletion and intoxication have occurred; the latter was twice precipitated by Calcium Sandoz tablets given for bone disease $\left(\mathrm{KHCO}_{3} \stackrel{\rho}{\rightleftharpoons}\right.$ provides the "fizz").

The most serious complication has been acute pyelonephritis, which killed three of our patients and severely compromised 
renal function in a fourth. Since pyuria is of little value in diagnosing infection in this condition, reliance must be placed solely on regular midstream urine culture. The $14 \%$ of positive cultures we have obtained includes "repeats" and is no higher than in some surveys of hospital female patients without known renal disease. Bladder infection, however, is a much greater hazard in these patients with necrotic tissue in the renal pelves than in the general population, and we have treated positive midstream urine cultures on suspicion.

We thank the many family doctors, physicians, and surgeons who have supplied details of the early history of these patients. We are grateful to Professor A. L. Latner, Dr. A. Cassells-Smith, Dr, R. Ashcroft, Professor A. G. Hepplestone, Dr. C. K. Warrick, Dr. T. R. Harlen, and their respective staffs for the biochemical, pathological, and radiological data quoted.

ADDENDUM.-Since submitting this report one patient (Case 2) has died from myocardial infarction and pulmonary oedema. The kidneys showed typical changes of analgesic nephropathy with calcified papillae and a combined weight of only $90 \mathrm{~g}$.
REFERENCES

Bengtsson, U. (1967). In Proceedings of the Third International Congress of Nephrology, edited by G. E. Schreiner, vol. 2, p. 291 Basel, Karger.

Bulger, R. J. Healey, L. A., and Polinsky, P. (1968). Annals of the Rheumatic Diseases, 27, 339.

Burry, A. F., de Jersey, P., and Weedon, D. (1966). Medical fournal of Australia, 1, 873

Fairley, K. F., and Kincaid-Smith, P. (1968). British Medical fournal, 1, 156

Gault, M. H., Rudwal, T. C., Engles, W. D., and Dossetor, J. B. (1968), Annals of Internal Medicine, 68, 906.

Gilman, A. (1964). American fournal of Medicine, 36, 167.

Harvald, B. (1963). American Fournal of Medicine, 35, 481.

Kincaid-Smith, P. (1967). Lancet, 1, 859.

Krikler, D. M. (1967). British Medical fournal, $2,615$.

Larsen, K., and Møller, C. E. (1959). Acta Medica Scandinavica, 164 53 .

Lindvall. N. (1960). Acta Radiologica, Suppl. No. 192.

Lucke, V. M., Messervy, M., Lucke, J. N., and Hunt, A. C. (1968) Archives of Pathology, 86, 390.

Maisel, J. C., and Priest, R. E. (1964). Archives of Pathology, 77, 646.

Prescott, L. F. (1966). Lancet, 2, 1143.

Prescott, L. F. (1969). Scottish Medical fournal, 14, 82.

Walls, J., Bell, D., and Schorr, W. (1968). British Medical fournal, 2, 52.

Young, J. V., Haydon, G. B., Gray, C. P., Hecker, S. P., and Lee, P. R (1965). Annals of Internal Medicine, 62, 727.

\section{N. L. BROWSE, ${ }^{*}$ M.D., F.R.C.S. ; M. LEA THOMAS, $†$ M.A., M.R.C.P., F.F.R. ; M. J. SOLAN, $\ddagger$ M.B., F.R.c.s. ;} A. E. YOUNG,§ M.A., M.B., B.CHIR.

Cummary : Fifty patients have been studied by bilateral phlebography following their first, or sometimes recurrent, pulmonary embolus. Nineteen were found to have fresh loose peripheral thrombus, and in eight of them the thrombus looked big enough to cause a major pulmonary artery obstruction and death. These 19 patients were treated by vein ligation in addition to anticoagulants.

The incidence of recurrent embolism in the trial group is significantly lower than that found in a retrospective study of 50 patients treated with anticoagulants only. It is suggested that anticoagulants will not prevent all recurrent pulmonary emboli, and that phlebography, and if necessary surgery, should be part of the routine investigation and treatment of all patients after their first pulmonary embolus.

\section{Introduction}

Pulmonary embolism kills at least 2,500 people in Great Britain every year (Registrar General Report, 1967). It contributes towards the deaths of many more, and a proportion of these deaths follow the second or third embolus. Barker and Priestly (1942) reviewed the natural history of 1,665 cases of postoperative thromboembolism and found that $30 \%$ of patients who survived a pulmonary embolus had a second embolus; this was fatal in $19 \%$.

\footnotetext{
* Assistant Director, Surgical Unit.

† Consultant Radiologist.

¥ Senior Surgical Registrar.

House Surgeon.

St. Thomas's Hospital, London S.E.1.
}

It is claimed (Table I) that the use of intravenous heparin will reduce the mortality rate after embolism and also the incidence of second emboli, but the published facts do not entirely support this view. For example, though Barritt and Jordan (1960) had no fatal recurrences in a series of 54 patients treated with heparin and nicoumalone, Ochsner et al. (1951) had a second fatal embolus rate of $11 \cdot 7 \%$. Nevertheless, the figures from almost every publication support the claim that heparin reduces the mortality rate after embolus. The effect of anticoagulants on the non-fatal recurrence rate is not clear. It is obvious from Table I that though the number of recurrences may be reduced they still occur frequently. Those who believe heparin to be the best treatment for pulmonary embolism often suggest that anticoagulation was insufficient in the series with high recurrence rates. This may be true, but it is noteworthy that the clotting-time was not measured in the majority of the papers mentioned in Table I, and there is no correlation between those that measured the effect of heparin and the results.

The alternative to anticoagulants is vein ligation. Blind bilateral superficial femoral vein ligation and vena cava plication and ligation have all been tried (Table I) and have had significant recurrence rates. Vena cava ligation is the most effective surgical measure but is associated with a definite incidence of leg swelling and postphlebitic complications (Dale, 1962). Both Fontaine (1957) and Coon et al. (1958) mention the possibility of combining anticoagulants and vein ligation, but no results of this approach have been published.

Our interest in this problem began when we were asked to perform vena cava ligations on a number of patients who had recurrent emboli while being given anticoagulants. We felt this was a blind and often unnecessary procedure and decided to 